\title{
Profile of bevacizumab in the treatment of platinum- resistant ovarian cancer: current perspectives
}

\author{
This article was published in the following Dove Press journal: \\ International Journal of Women's Health \\ 15 March 2016 \\ Number of times this article has been viewed
}

\section{E Clair McClung \\ Robert MWenham}

Department of Gynecologic Oncology, H. Lee Moffitt Cancer Center, Tampa, FL, USA
Correspondence: Robert M Wenham Department of Gynecologic Oncology, H. Lee Moffitt Cancer Center, 12902 Magnolia Drive, MCC-3057 GYN, Tampa, FL 33612, USA

$\mathrm{Tel}+\mathrm{I} 8137455739$

Fax +I 8I37457228

Email robert.wenham@moffitt.org

\begin{abstract}
Patients with platinum-resistant ovarian cancer have progression of disease within 6 months of completing platinum-based chemotherapy. While several chemotherapeutic options exist for the treatment of platinum-resistant ovarian cancer, the overall response to any of these therapies is $\sim 10 \%$, with a median progression-free survival of 3-4 months and a median overall survival of 9-12 months. Bevacizumab (Avastin), a humanized, monoclonal antivascular endothelial growth factor antibody, has demonstrated antitumor activity in the platinum-resistant setting and was recently approved by US Food and Drug Administration for combination therapy with weekly paclitaxel, pegylated liposomal doxorubicin, or topotecan. This review summarizes key clinical trials investigating bevacizumab for recurrent, platinum-resistant ovarian cancer and provides an overview of efficacy, safety, and quality of life data relevant in this setting. While bevacizumab is currently the most studied and clinically available antiangiogenic therapy, we summarize recent studies highlighting novel alternatives, including vascular endothelial growth factor-trap, tyrosine kinase inhibitors, and angiopoietin inhibitor trebananib, and discuss their application for the treatment of platinum-resistant ovarian cancer.
\end{abstract}

Keywords: bevacizumab, angiogenesis, ovarian cancer, platinum-resistant ovarian cancer, recurrent ovarian cancer

\section{Introduction}

Approximately 225,000 new cases of ovarian cancer are diagnosed worldwide, and $\sim 140,200$ women die of the disease each year. ${ }^{1}$ When compared to other solid tumors, ovarian cancer has a strong proclivity for early peritoneal dissemination and a disproportionately high percentage of women present with advanced stage disease. A combination of maximal surgical cytoreduction and platinum-taxane-based chemotherapy comprises the mainstay of primary therapy. Approximately $75 \%$ of patients experience an initial complete clinical response, but the majority recur, with a median time to first recurrence of 16 months. ${ }^{2}$ The behavior of recurrent ovarian cancer is variable. Recurrent tumors can be isolated or widely metastatic and relatively indolent, or rapidly progressing. Unfortunately, recurrent ovarian cancers are rarely curable. The primary goals of therapy are to prolong disease-free intervals and to improve the quality of life.

Responsiveness to chemotherapy and length of remission are predictors of overall prognosis. ${ }^{3}$ Patients with recurrent ovarian cancer are risk stratified based on the time to recurrence after the completion of platinum-based chemotherapy: patients with a treatment-free interval of $>6$ months after the completion of primary platinum-based therapy are considered as platinum sensitive and patients with a treatment-free interval of $<6$ months are considered as platinum resistant. Patients who progress while on therapy or within 4 weeks of platinum-based therapy are generally considered as

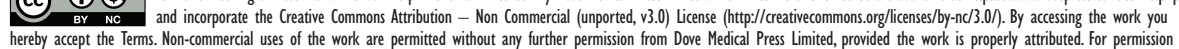
for commercial use of this work, please see paragraphs 4.2 and 5 of our Terms (https://www.dovepress.com/terms.php). 
platinum refractory. With successive lines of chemotherapy, most tumors eventually become platinum resistant or refractory.

Several chemotherapeutic options exist for the treatment of platinum-resistant ovarian cancer, including pegylated liposomal doxorubicin (PLD), ${ }^{4,5}$ gemcitabine, ${ }^{5,6}$ topotecan, ${ }^{4}$ and etoposide. ${ }^{7,8}$ The overall response to any of these therapies is $\sim 10 \%-20 \%$, with a median progression-free survival (PFS) of 3-4 months and a median overall survival (OS) of 9-12 months. ${ }^{3}$ Selection of therapy depends on prior treatment history, patient characteristics, and the side effect profile of each drug. More therapeutic options are desperately needed.

Bevacizumab (Avastin, Genentech, San Francisco, CA, USA), a monoclonal anti-vascular endothelial growth factor (VEGF)-A antibody targeting tumor angiogenesis, has been investigated and widely adopted for the treatment of recurrent ovarian cancer for the last several years. On November 14, 2014, following the publication of Phase III Avastin Use in Platinum-Resistant Epithelial Ovarian Cancer (AURELIA) trial, ${ }^{9}$ the US Food and Drug Administration (FDA) approved bevacizumab for use in recurrent, platinum-resistant ovarian cancer. Bevacizumab is the first new drug to receive FDA approval for the treatment of ovarian cancer since gemcitabine (in combination with carboplatin) in 2006. Bevacizumab, in combination with PLD, weekly paclitaxel, or topotecan, is currently approved for patients with platinum-resistant disease who have received no more than two previous lines of chemotherapy. This review focuses on the efficacy, safety, acceptability, and therapeutic role of bevacizumab for the treatment of recurrent, platinum-resistant ovarian cancer.

\section{Bevacizumab}

Tumor angiogenesis plays a pivotal role in the growth and metastasis of ovarian cancer, because of the unique pattern of early dissemination of free-floating cells that form tumor implants in the peritoneal cavity. In order for a tumor to grow $>1-2 \mathrm{~mm}$ in size, it must recruit a blood supply from surrounding host tissue. ${ }^{10}$ Tumors that fail to develop an adequate blood supply may remain quiescent for many years. An angiogenic switch, which is associated with an increased growth and metastatic potential, occurs when tumors become vascularized. ${ }^{11}$ Angiogenic switch occurs as a result of alterations in the tumor-stromal microenvironment induced by the activation of tumor oncogenes, tissue hypoxia, and increased tumor expression of multiple proangiogenic factors, including VEGF, fibroblast growth factor (FGF), platelet-derived growth factor (PDGF), angiopoietins (Ang1 and Ang2), and others.
VEGF-A is one of the most important regulators of angiogenesis, which was first isolated in $1983^{12}$ and independently verified in $1989 .{ }^{13}$ We now know that VEGF-A is one of a family of seven soluble VEGF ligands (VEGFA-E and placental growth factor-1 and -2) that bind and signal through cell surface receptor tyrosine kinases VEGF receptor (VEGFR)-1, VEGFR-2, and VEGFR-3 with variable affinities and effects depending on the biological context. ${ }^{14,15}$ VEGF-A preferentially binds VEGFR-1 and VEGFR-2, which are the most important receptors for VEGFA-mediated angiogenesis. ${ }^{16}$ VEGF-A signaling through VEGFR-2 promotes endothelial cell proliferation and resistance to apoptosis through c-Raf-MAPK/ERK kinase and $\mathrm{PI} 3 \mathrm{~K} / \mathrm{AKT}$ signaling pathway activation ${ }^{17,18}$ and induces microvascular permeability, contributing to the extravasation of plasma proteins and water into the tumor microenvironment. ${ }^{19}$ This in turn creates a favorable environment for cell migration and proliferation, enhancing endothelial cell migration and neovascularization of the tumor-associated stroma, as well as tumor growth and metastasis. Increased capillary permeability also contributes to the formation of malignant ascites, and VEGF concentrations in malignant ascites, which is common in ovarian cancer, exceed the 95 th percentile of concentrations observed in benign diseases. ${ }^{20}$

In ovarian cancers, VEGF is detectable by immunohistochemistry in ovarian tumors, as well as in ascites and serum samples, and the expression levels are cancer specific, with no expression in benign ovarian tumors, intermediate expression in borderline tumors, and high levels of expression in invasive cancers. ${ }^{21,22}$ VEGF expression also correlates with ovarian cancer stage at diagnosis and shorter PFS and OS. ${ }^{23-25}$

Mouse monoclonal anti-VEGF-A antibodies were shown to dramatically reduce tumor growth and malignant ascites formation in vivo, leading to the development of bevacizumab, a humanized monoclonal anti-VEGF-A antibody, in $1997 .{ }^{26}$ Bevacizumab demonstrated a promising activity against advanced colorectal cancers, which quickly led to multiple studies in breast, renal, cervical, and ovarian carcinomas.

Bevacizumab was first demonstrated to have an activity as monotherapy in recurrent ovarian cancer in 2007. There are now four published Phase III randomized controlled trials ${ }^{9,27-29}$ examining bevacizumab in ovarian cancer: two in the frontline setting, one in platinum-sensitive recurrent disease, and one in platinum-resistant disease. In Gynecologic Oncology Group (GOG) 218, 1,873 women with stage III or IV previously untreated and incompletely resected ovarian cancer were randomized to the first-line adjuvant therapy in one of the three arms after primary 
surgical cytoreduction: control (carboplatin area under the concentration [AUC] 6 plus paclitaxel $175 \mathrm{mg} / \mathrm{m}^{2}$ plus placebo), control with bevacizumab $15 \mathrm{mg} / \mathrm{kg}$, or control with bevacizumab followed by bevacizumab maintenance. ${ }^{27}$ Combination of bevacizumab therapy with bevacizumab maintenance therapy resulted in an improved PFS (median PFS 14.1 months vs 10.3 months without bevacizumab, hazard ratio [HR] $0.717,95 \%$ confidence interval [CI] $0.625-0.824, P<0.001$ ), but there was no difference in OS. ICON7, a very similar trial, evaluated bevacizumab for the first-line adjuvant therapy after primary surgery in women with stages I-IIA high-grade or clear cell ovarian carcinoma or stages IIB-IV epithelial ovarian cancer, primary peritoneal cancer, or fallopian tube cancer. (Epithelial ovarian cancer, primary peritoneal cancer, and fallopian tube cancer share similar carcinogenesis, pattern of spread, staging, and treatment and are frequently combined with clinical trials. These three diseases will be referred to as ovarian cancer in this review.) ICON7 randomized 1,528 women for firstline adjuvant therapy with carboplatin (AUC 5 or 6 ) plus paclitaxel $175 \mathrm{mg} / \mathrm{m}^{2}$ every 3 weeks for six cycles or this regimen plus bevacizumab $7.5 \mathrm{mg} / \mathrm{kg}$ given concurrently. ${ }^{28}$ A subset of 470 women in the bevacizumab arm received an additional 12 cycles of bevacizumab maintenance therapy. In updated analysis after 28 months of median follow-up, PFS was significantly improved with the addition of bevacizumab therapy (median PFS 19.8 months vs 17.4 months, HR $0.87,95 \%$ CI $0.77-0.99, P=0.04$ ), but there was no statistically significant improvement in OS. With two large randomized trials demonstrating modest improvement in PFS with no difference in OS, bevacizumab was not widely adopted for the first-line therapy outside of clinical trials. Further discussion on the role of bevacizumab in the firstline therapy is beyond the scope of this review and can be found elsewhere.

GOG 218 and ICON7 were followed by two trials evaluating bevacizumab in the recurrent setting. Ovarian Cancer Study Comparing Efficacy and Safety of Chemotherapy and Anti-Angiogenic Therapy in Platinum-Sensitive Recurrent Disease (OCEANS) randomized 484 women with recurrent, platinum-sensitive ovarian, fallopian tube, and primary peritoneal cancer to carboplatin (AUC 4) on day 1 with gemcitabine $1,000 \mathrm{mg} / \mathrm{m}^{2}$ on days 1 and 8 , with bevacizumab $15 \mathrm{mg} / \mathrm{kg}$ or placebo. Bevacizumab was significantly associated with an increased PFS (median PFS 12.4 months vs 8.4 months, HR $0.484,95 \% \mathrm{CI} 0.388-0.605, P<0.0001),{ }^{29}$ but there was no significant difference in OS. ${ }^{30}$ Most recently, the AURELIA trial demonstrated a significant improvement in PFS for women with platinum-resistant ovarian cancer (Table 1). ${ }^{9}$

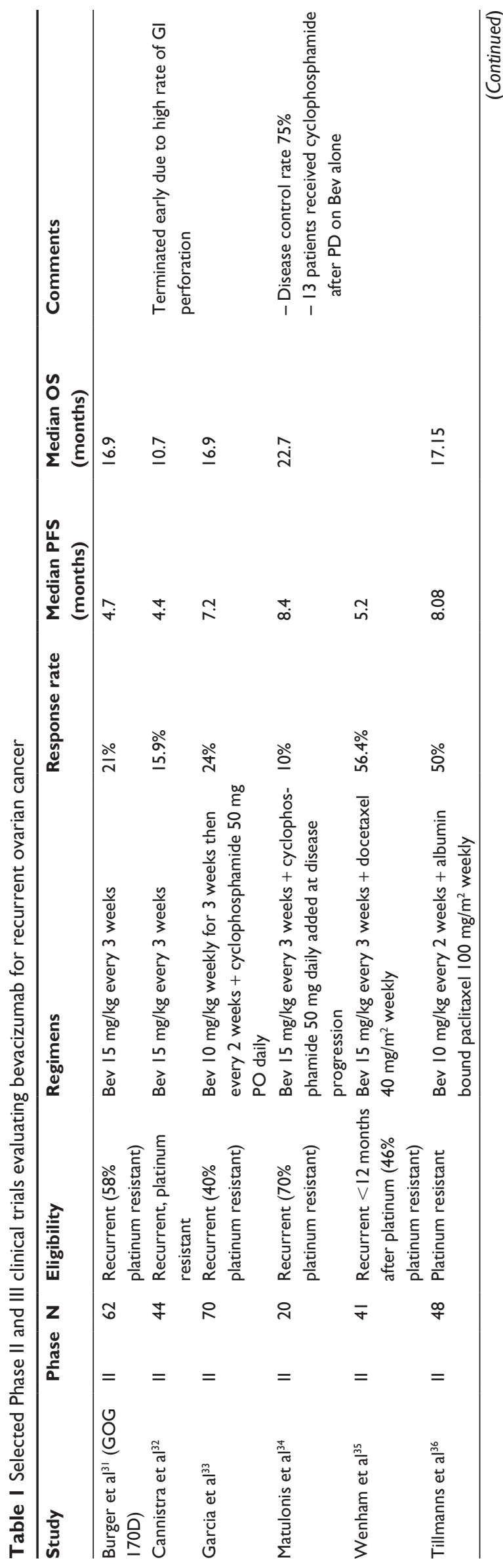




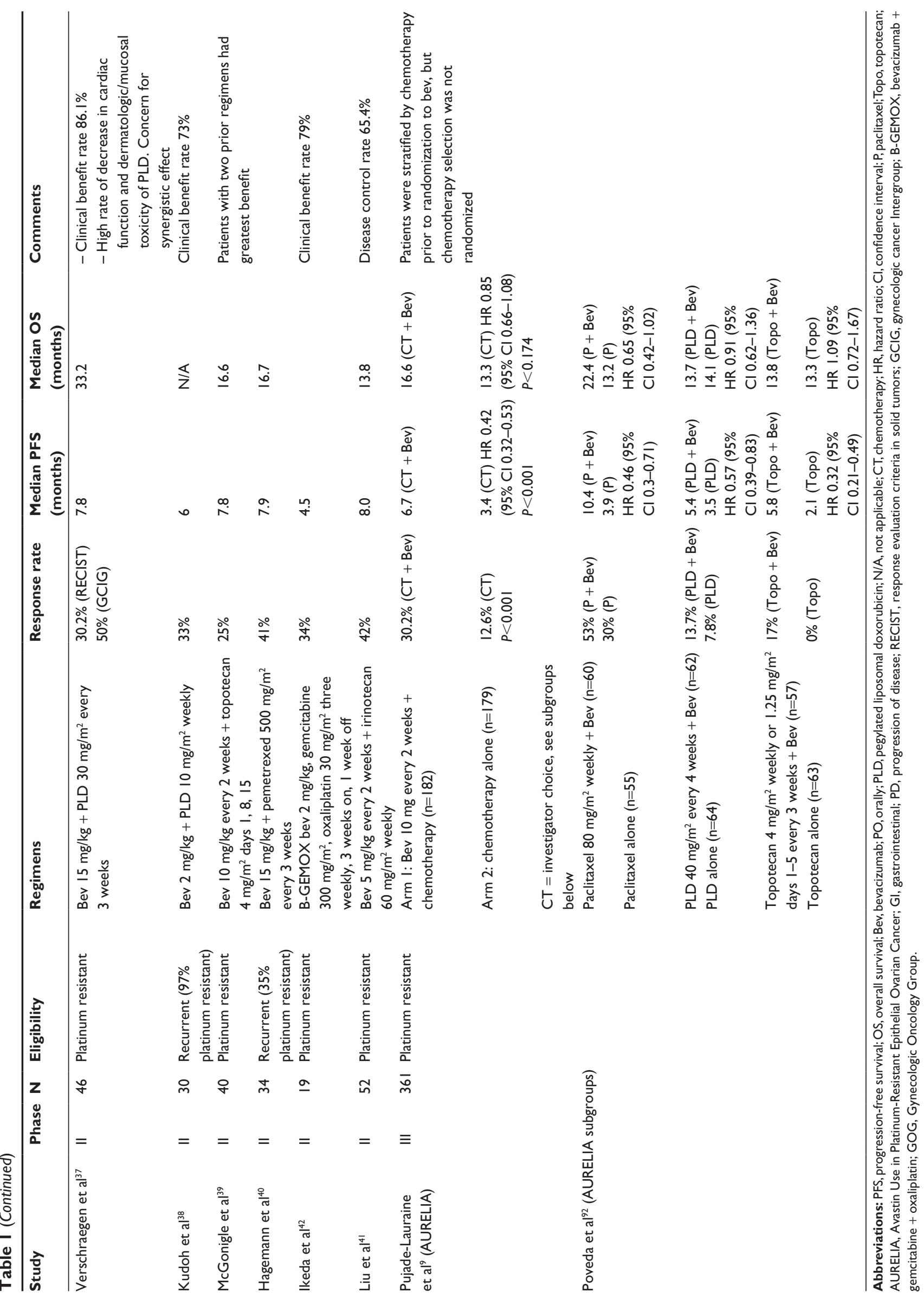




\section{Efficacy of bevacizumab in recurrent, platinum-resistant ovarian cancer}

GOG 170D was the first of two concurrent phase II trials published in 2007 that demonstrated a promising bevacizumab activity in ovarian cancer. In this study, Burger et al reported an objective response rate (ORR) of 21\% among 62 evaluable patients with recurrent ovarian cancer who received bevacizumab $15 \mathrm{mg} / \mathrm{kg}$ every 3 weeks until disease progression or unacceptable toxicity. ${ }^{31}$ Of note, there were no gastrointestinal (GI) perforations observed in this study. GOG 170D was originally designed to evaluate 6 months PFS but was reopened to evaluate ORR after an unanticipated high rate of clinical responses. There were two complete responses and eleven partial responses, with a median duration of response of 10.3 months, and 31 patients maintained stable disease. Response rates among platinum-resistant patients, who accounted for $58 \%$ of the study group, were not specifically reported. An exploratory analysis of prognostic factors predicting response found no significant association between response and platinum sensitivity. ${ }^{31}$

Shortly after GOG 170D, Cannistra et al reported an ORR of $15.9 \%$ among 44 women with recurrent, platinumresistant ovarian cancer who received bevacizumab $15 \mathrm{mg} / \mathrm{kg}$ every 3 weeks. $^{32}$ An additional $61.4 \%$ experienced stable disease. Despite early termination due to an unexpectedly high rate of GI perforation (11.4\%), Cannistra et al reported a response rate comparable to other single-agent therapies in the recurrent, platinum-resistant setting. Median PFS was 4.4 months, and median OS was 10.7 months at the time of study termination.

Following upon the Burger et al and Cannistra et al studies, multiple Phase II clinical trials have evaluated bevacizumab as a doublet with other cytotoxic drugs that are frequently used for recurrent ovarian cancer. ORRs range from $24 \%$ to $50 \%$ in the studies of $>20$ patients. PFS ranges from 6 months to 8 months, and OS ranges from 13.8 months to 33.2 months (Table 1) ${ }^{33-42}$ The majority of these trials include both platinum-sensitive and platinumresistant patients; however, there are five trials specifically evaluating platinum-resistant patients with similar response rates and survival outcomes. ${ }^{36,37,39,41,42}$ In addition to the encouraging ORRs observed with bevacizumab, Phase II studies also demonstrate high rates of disease stabilization, which is an important consideration for the platinum-resistant population, where therapeutic options are limited and where prolonged stable disease allows patients to maintain a reasonable quality of life while managing their cancer as a chronic illness.
In all Phase II studies of bevacizumab combination therapy, ORRs, PFS, and OS compare favorably with the previous studies of cytotoxic chemotherapy for recurrent, platinum-resistant ovarian cancer. The AURELIA trial is the first Phase III clinical trial to directly compare bevacizumab combined with chemotherapy to chemotherapy alone in the recurrent, platinum-resistant setting. ${ }^{9}$ A total of 361 patients with recurrent ovarian, fallopian tube, and primary peritoneal cancer who progressed within 6 months of receiving platinum-based chemotherapy were assigned a single-agent chemotherapy from the following options based on the investigator choice: 1) weekly paclitaxel $80 \mathrm{mg} / \mathrm{m}^{2}$, 2) PLD $40 \mathrm{mg} / \mathrm{m}^{2}$ every 4 weeks, or 3) topotecan $4 \mathrm{mg} / \mathrm{m}^{2}$ on days 1,8 , and 15 every 4 weeks or $1.25 \mathrm{mg} / \mathrm{m}^{2}$ on days $1-5$ every 3 weeks (Table 1). Patients were stratified by chemotherapy regimen prior to randomization to bevacizumab combination therapy or chemotherapy alone. The addition of bevacizumab resulted in an ORR of $30.9 \%$, compared to $12.6 \%$ for chemotherapy alone $(P<0.001)$, and a median PFS of 6.7 months vs 3.4 months (HR $0.48,95 \%$ CI $0.38-0.60, P<0.001$ ). There was a nonsignificant trend toward an improved OS (16.6 months vs 13.3 months, HR $0.85,95 \%$ CI $0.66-1.08$, $P<0.174)$; however, the true effect of bevacizumab on OS is obscured and likely diluted by a $40 \%$ crossover to bevacizumab monotherapy among patients in the chemotherapy arm at the time of disease progression.

Subgroup analysis of the AURELIA trial confirmed that bevacizumab consistently improves ORR and PFS across chemotherapy cohorts (Table 1). Interestingly, the ORR associated with bevacizumab combination therapy was the highest in the paclitaxel cohort (53.3\% vs 30.2\%) compared to topotecan ( $17 \%$ vs $0 \%)$ and the PLD $(13.7 \%$ vs $7.8 \%)$. Median PFS followed the same trend for paclitaxel (10.4 months vs 3.9 months, HR $0.46,95 \%$ CI $0.3-0.71$ ), topotecan (5.8 months vs 2.1 months, HR $0.3295 \%$ CI $0.21-0.49$ ), and PLD (5.4 months vs 3.5 months, HR $0.57,95 \%$ CI $0.93-0.83$ ).

It would be erroneous to conclude from these subgroup analyses of AURELIA that there is a superiority of one of these chemotherapies given that the trial design did not randomize the chemotherapeutic agent. However, the potential for a more pronounced treatment effect with paclitaxel is intriguing. This trend is also present among Phase II studies of bevacizumab combination therapy (Table 1) and may reflect a higher activity of frequently dosed taxanes in epithelial ovarian cancer. Such a metronomic schedule of some chemotherapies may also provide antiangiogenic effects not seen with conventional dosing schedules. ${ }^{43,44}$ Additionally, metronomic dosing, such as with oral daily cyclophosphamide, may also impart immunostimulatory effects. ${ }^{45,46}$ 
A few studies have examined bevacizumab in combination with other targeted biologic therapies in recurrent ovarian cancer. Epidermal growth factor receptor activation has been shown to promote VEGF secretion; therefore, Nimeiri et al reported a small Phase II clinical trial of combination of bevacizumab and erlotinib, which demonstrated no increased activity compared to the previous studies of bevacizumab alone, and an increased toxicity with a $15 \%$ rate of GI perforation and high rates of nausea and diarrhea. ${ }^{47}$ In a Phase I study by Azad et al, partial response was observed in 6/13 patients with ovarian cancer with a combination of bevacizumab $5 \mathrm{mg} / \mathrm{kg}$ every 2 weeks and sorafenib, a receptor tyrosine kinase inhibitor (TKI) known to target VEGFR-2 and Raf, which is known to be a downstream signaling target of VEGF. ${ }^{48}$ Rapid dose reductions for fatigue, anorexia, weight loss, hypertension, and proteinuria suggest that this combination may not be tolerable for long-term therapy, and 2/13 patients developed grade 2 fistulas.

\section{Safety and tolerability}

Bevacizumab is generally well accepted and tolerated by patients. The infusion can be completed within 30 minutes, ${ }^{49}$ and infusion-related side effects are rare, with serious infusion reactions occurring in $<0.2 \%$ based on the postmarketing data. ${ }^{50}$ The toxicities most attributed to bevacizumab include GI perforation, hypertension, proteinuria, venous thromboembolism (VTE), impaired wound healing, and bleeding. Rates of grade $\geq 3$ toxicity among patients with recurrent ovarian cancer in Phase II trials are summarized in Table 1. Despite the development of bevacizumab-related toxicites and recommendations for holding or discontinuing therapy in certain scenarios (such as described later in this section), it is recognized that the decision to do so may be complicated by the response to treatment, the prognosis and disease setting of the patient, and, often, the lack of reasonably effective alternatives.

Hypertension is the most common side effect of bevacizumab, followed by proteinuria, but these rarely lead to discontinuation of therapy. The rate of grade $\geq 3$ hypertension varies from $2 \%$ to $23 \%$ in ovarian cancer studies, ${ }^{51}$ with grade $\geq 2$ hypertension occurring in $20 \%$ of patients in the AURELIA trial. ${ }^{9}$ Proteinuria occurs in up to $64 \%$ of patients receiving bevacizumab, with the highest rates not surprisingly among patients with renal carcinoma. ${ }^{52}$ Management of hypertension and proteinuria can be guided by the National Cancer Institute grading system. ${ }^{51}$ Proteinuria can be monitored until reaching grade 3 severity $(>3.5 \mathrm{~g} / 24 \mathrm{~h}$ or urine protein-creatinine ratio $>3.5$ ), at which point bevacizumab may be held until protein levels return to grade 2 (1.0-3.5 g/24 h or urine protein-creatinine ratio 1-3.5). Bevacizumab may be discontinued for nephrotic syndrome. Proteinuria generally improves upon the discontinuation of bevacizumab. Grade 2 hypertension (systolic blood pressure [BP] 140-159 mmHg and diastolic BP 90-99 mmHg) may be addressed with antihypertensive medication. Grade 3 hypertension $(\mathrm{BP} \geq 160 \mathrm{mmHg}$ systolic or $\geq 100 \mathrm{mmHg}$ diastolic) may require escalation of antihypertensive medication, including multidrug therapy, and many doctors choose to hold bevacizumab until BPs return to grade 2 levels. Grade 4 hypertension describes life-threatening consequences requiring emergent management and discontinuation of bevacizumab. The mechanism behind bevacizumab-related hypertension is incompletely understood but may be related to the lower endogenous levels of nitric oxide, interaction with angiotensins I and II receptors, or functional loss of capillary vascular beds leading to an increased systemic vascular resistance. ${ }^{53,54}$ Proteinuria secondary to anti-VEGF therapy is thought to result from the disruption of VEGFdependent interactions between glomerular endothelial cells and podocytes, which in turn disrupts the filtration barrier. ${ }^{55}$ Renal thrombotic microangiopathy has also been described on renal biopsy, but systemic manifestations, such as thrombocytopenia and schistocytosis, are rare. ${ }^{55,56}$

The sequelae of uncontrolled hypertension include malignant hypertension, stroke, and posterior reversible leukoencephalopathy syndrome (PRES). PRES is a neurologic disorder characterized by the loss of cerebral vascular autoregulation and vasogenic edema. The diagnosis is made by the confirmation of posterior leukoencephalopathy on magnetic resonance imaging. Signs and symptoms include headache, seizures, lethargy, altered mental status, blindness, and other visual changes or alterations in neurologic function. There are at least 15 case reports of PRES associated with bevacizumab, some with fatal outcome, although many cases resolve with supportive care. ${ }^{57}$

GI perforation is probably the most publicized and concerning complication of bevacizumab therapy. The reported rate of GI perforation in recurrent ovarian cancer varies from $0 \%$ to $11.4 \%$; however, in large Phase III clinical trials, the rate of perforation is $0 \%-2.6 \%$. The rate of bowel perforation reported in clinical trials has decreased over time, which is believed to be, at least in part, due to the efforts to screen out patients at higher risk. In one of the earliest trials, Cannistra et al reported the highest rate of perforation (11.4\%), resulting in early termination of their study and a FDA investigational drug action letter reporting the GI perforation risk 
of bevacizumab among patients with ovarian cancer. In an unplanned retrospective subgroup analysis, the authors found that exposure to three or more prior chemotherapy regimens was the only significant characteristic associated with GI perforation, with $23.8 \%$ of patients in this group experiencing a perforation $(P<0.01) .{ }^{32}$ Retrospective studies associate bowel obstruction, bowel wall thickening or suspected bowel involvement, inflammatory bowel disease, and prior bowel surgery with increased rates of perforation..$^{51,58,59}$ If patients are screened for high-risk features, some GI perforations may be prevented. Studies reporting $0 \%$ perforation rates include $<100$ patients, and the absence of perforation is likely related to sample size. In the AURELIA trial, patients with more than two prior lines of chemotherapy, bowel obstruction, or evidence of rectosigmoid tumor involvement were excluded, resulting in a GI perforation rate of $2 \% .{ }^{9}$ Patients without risk factors should be closely monitored. GI perforations carry a high rate of mortality, especially in the setting of recurrent, platinum-resistant ovarian cancer. Many such patients have been heavily pretreated and carry a significant burden of peritoneal disease, with marginal nutritional and functional status, and may not tolerate or benefit from surgical exploration and repair. Therefore, a bowel perforation is a sentinel event that often leads to the discontinuation of further anticancer therapy and a transition to comfort care.

Thromboembolic adverse events are reported in most trials of bevacizumab. However, the true elevation in the risk above the baseline risk associated with metastatic carcinoma is somewhat controversial. Based on a pooled analysis of 1,745 patients with metastatic colorectal, breast and nonsmall-cell lung cancers, the addition of bevacizumab to standard chemotherapy is associated with an increased risk of arterial thromboembolic events (HR 2.0, 95\% CI 1.05-3.75, $P=0.031$ ), but there was no increase in VTE (HR $0.89,95 \%$ CI $0.66-1.20, P=0.44) .{ }^{60}$ The rates of arterial thromboembolic events, including transient ischemic attacks, ischemic stroke, and myocardial infarction, are low among patients with ovarian cancer, but all patients receiving bevacizumab should be considered at risk and monitored for symptoms. In the AURELIA trial, chemotherapy plus bevacizumab vs chemotherapy alone led to $\geq$ grade 3 arterial or venous thromboembolic events in $2 \%$ vs $0 \%$ and $3 \%$ vs $4 \%$ of patients, respectively. ${ }^{9}$ Many oncologists believe that patients who experience a VTE (deep vein thrombosis or pulmonary embolus) may continue bevacizumab as long as therapeutic anticoagulation has been initiated.

Wound-healing complications related to bevacizumab are less commonly reported in ovarian cancer trials because initiation of bevacizumab is delayed at least 4-6 weeks after surgery (as in GOG 218 and ICON7 when bevacizumab was not initiated until cycle 2). In the BRiTE registry, which monitors postmarket outcomes among patients with colorectal cancer who receive bevacizumab in the community, 23/622 (3.7\%) of patients who reported having a major surgery within 60 days of bevacizumab experienced wound complications. ${ }^{61}$ Because of bleeding risk and impaired wound healing, the manufacturer recommends at least 4 weeks between bevacizumab and any major operative procedures. ${ }^{50}$ Mucosal bleeding and epistaxis are commonly reported by patients receiving bevacizumab, but serious GI bleeding and perioperative hemorrhage have also been reported.

In combination with cytotoxic chemotherapy, hematologic, GI, dermatologic, and mucosal side effects are more likely to arise from cytotoxic chemotherapy exposure. Verschraegen et al reported a concern for synergistic amplification of mucosal, cutaneous, and cardiac toxicity in a Phase II trial of bevacizumab with PLD $30 \mathrm{mg} / \mathrm{m}^{2}$ given every 3 weeks. ${ }^{37}$ A total of $16 \%$ of patients experienced some degree of cardiac insufficiency. Concern for synergistic toxicity has not been reported in other trials. Bowel perforation occurred in 4/100 heavily pretreated patients with ovarian cancer at 7-14 days after paclitaxel infusion, ${ }^{62}$ but this was not recapitulated in subsequent clinical trials, and rates of perforation with combination therapy fall within the range reported for bevacizumab alone and in combination with many different chemotherapies (Table 2).

\section{Patient focused perspectives and quality of life}

Because chemotherapy for platinum-resistant recurrent ovarian cancer is rarely curative, the quality of life is an important consideration in the choice of therapy. The quality of life outcomes from ICON7 and GOG 218, two large Phase III trials evaluating bevacizumab in the primary adjuvant setting, suggest no difference during chemotherapy, with a slight decrement in the quality of life related to continuation of maintenance bevacizumab in ICON7 among patients who remained progression free after adjuvant therapy. ${ }^{63,64}$ In contrast, patient-reported outcomes were improved with the addition of bevacizumab to standard chemotherapy for patients with recurrent, platinum-resistant disease in the AURELIA trial. ${ }^{65}$ The disparity in these findings may relate to differences in disease burden and pretreatment quality of life among patients receiving primary therapy after debulking surgery when compared to patients with recurrent disease. GI symptoms, including nausea, bloating, constipation, and 
Table 2 Toxicity of bevacizumab in recurrent ovarian cancer

\begin{tabular}{|c|c|c|c|c|c|}
\hline Study & Phase & $\mathbf{N}$ & Eligibility & Regimens & $\begin{array}{l}\text { Grade } 3-4 \text { toxicities in patients } \\
\text { receiving bevacizumab }\end{array}$ \\
\hline $\begin{array}{l}\text { Burger et al }{ }^{31} \text { (GOG } \\
\text { I70D) }\end{array}$ & II & 62 & $\begin{array}{l}\text { Recurrent ( } 58 \% \\
\text { platinum resistant) }\end{array}$ & Bev $15 \mathrm{mg} / \mathrm{kg}$ every 3 weeks & $\begin{array}{l}\text { - GI perforation }(0 \%) \\
\text { - HTN }(9.7 \%) \\
\text { - VTE }(1.6 \%) \\
\text { - GI }(<5 \%) \\
\text { - GU }(1.6 \%)\end{array}$ \\
\hline Cannistra et a ${ }^{32}$ & II & 44 & $\begin{array}{l}\text { Recurrent, platinum } \\
\text { resistant }\end{array}$ & Bev $15 \mathrm{mg} / \mathrm{kg}$ every 3 weeks & $\begin{array}{l}\text { - Gl perforation (I I\%) } \\
\text { - HTN (9\%) } \\
\text { - Dyspnea (4.5\%) } \\
\text { - Fatigue }(4.5 \%) \\
\text { - Gl }(4.5 \%)\end{array}$ \\
\hline Garcia et $\mathrm{al}^{33}$ & II & 70 & $\begin{array}{l}\text { Recurrent }(40 \% \\
\text { platinum resistant) }\end{array}$ & $\begin{array}{l}\text { Bev } 10 \mathrm{mg} / \mathrm{kg} \text { weekly for } \\
3 \text { weeks then every } 2 \text { weeks + } \\
\text { cyclophosphamide } 50 \mathrm{mg} \text { PO } \\
\text { daily }\end{array}$ & $\begin{array}{l}\text { - GI perforation (2.9\%) } \\
\text { - GI fistula (I.4\%) } \\
\text { - Wound complication (I.4\%) } \\
\text { - GI bleeding (I.4\%) } \\
\text { - HTN (I6\%) } \\
\text { - Hematologic }(23 \%)\end{array}$ \\
\hline Matulonis et al ${ }^{14}$ & II & 20 & $\begin{array}{l}\text { Recurrent }(70 \% \\
\text { platinum resistant) }\end{array}$ & $\begin{array}{l}\text { Bev } 15 \mathrm{mg} / \mathrm{kg} \text { every } 3 \text { weeks + } \\
\text { cyclophosphamide } 50 \mathrm{mg} \text { daily } \\
\text { added at PD }\end{array}$ & $\begin{array}{l}\text { - GI perforation (5\%) } \\
- \text { MI }(5 \%) \\
- \text { HTN }(60 \%)\end{array}$ \\
\hline Wenham et $\mathrm{al}^{35}$ & II & 41 & $\begin{array}{l}\text { Recurrent }<12 \text { months } \\
\text { after platinum ( } 46 \% \\
\text { platinum resistant) }\end{array}$ & $\begin{array}{l}\text { Bev } 15 \mathrm{mg} / \mathrm{kg} \text { every } 3 \text { weeks + } \\
\text { docetaxel } 40 \mathrm{mg} / \mathrm{m}^{2} \text { weekly }\end{array}$ & $\begin{array}{l}\text { - Gl perforation }(2.4 \%) \\
\text { - GI fistula }(2.4 \%) \\
\text { - Hematologic }(14.6 \%) \\
\text { - Neuropathy }(4.9 \%) \\
\text { - GI }(9.8 \%)\end{array}$ \\
\hline Tillmanns et $\mathrm{a}^{36}$ & II & 48 & Platinum resistant & $\begin{array}{l}\text { Bev } 10 \mathrm{mg} / \mathrm{kg} \text { every } 2 \text { weeks + } \\
\text { albumin bound paclitaxel } \\
100 \mathrm{mg} / \mathrm{m}^{2} \text { weekly }\end{array}$ & $\begin{array}{l}\text { - GI perforation (4.2\%) } \\
\text { - Hematologic (I0.5\%) } \\
\text { - GI }(26.3 \%) \\
\text { - HTN }(6.3 \%) \\
\text { - VTE }(4.2 \%)\end{array}$ \\
\hline Verschraegen et $\mathrm{a}^{37}$ & II & 46 & Platinum resistant & $\begin{array}{l}\text { Bev } 15 \mathrm{mg} / \mathrm{kg}+\text { PLD } 30 \mathrm{mg} / \mathrm{m}^{2} \\
\text { every } 3 \text { weeks }\end{array}$ & $\begin{array}{l}\text { - GI perforation }(0 \%) \\
\text { - HTN }(30 \%) \\
\text { - Headache (II\%) } \\
\text { - Dermatologic (39\%) } \\
\text { - Mucositis }(9 \%) \\
\text { - Hemolytic uremic syndrome (2\%) } \\
\text { - Wound dehiscence }(2 \%) \\
\text { - Neurologic }(2 \%) \\
\text { - Renal }(2 \%) \\
\text { - Cardiac }(2 \%)\end{array}$ \\
\hline Kudoh et $\mathrm{al}^{38}$ & II & 30 & $\begin{array}{l}\text { Recurrent }(97 \% \\
\text { platinum resistant) }\end{array}$ & $\begin{array}{l}\text { Bev } 2 \mathrm{mg} / \mathrm{kg}+\text { PLD } \\
10 \mathrm{mg} / \mathrm{m}^{2} \text { weekly }\end{array}$ & $\begin{array}{l}\text { - Gl perforation }(3 \%) \\
\text { - Hand foot syndrome }(3 \%)\end{array}$ \\
\hline McGonigle et $\mathrm{a}^{39}$ & II & 40 & Platinum resistant & $\begin{array}{l}\text { Bev } 10 \mathrm{mg} / \mathrm{kg} \text { every } 2 \text { weeks + } \\
\text { topotecan } 4 \mathrm{mg} / \mathrm{m}^{2} \text { days I, } 8 \text {, } \\
\text { and } 15\end{array}$ & $\begin{array}{l}\text { - Gl perforation (0\%) } \\
\text { - Neutropenia (I8\%) } \\
\text { - HTN (20\%) } \\
\text { - GI (I8\%) } \\
\text { - VTE }(3 \%) \\
\text { - Proteinuria (3\%) }\end{array}$ \\
\hline Hagemann et a $\left.\right|^{40}$ & II & 34 & $\begin{array}{l}\text { Recurrent ( } 35 \% \\
\text { platinum resistant) }\end{array}$ & $\begin{array}{l}\text { Bev } 15 \mathrm{mg} / \mathrm{kg}+\text { pemetrexed } \\
500 \mathrm{mg} / \mathrm{m}^{2} \text { every } 3 \text { weeks }\end{array}$ & $\begin{array}{l}\text { - Neutropenia (50\%) } \\
\text { - Thrombocytopenia (I2) } \\
\text { - Anemia (9\%) } \\
\text { - Febrile neutropenia (3\%) } \\
\text { - Impaired coagulation (6\%) } \\
\text { - Cardiac (3\%) } \\
\text { - GI (I2\%) } \\
\text { - Pain (2I\%) } \\
\text { - Neurologic (3\%) } \\
\text { - Metabolic }(24 \%) \\
\text { - Hemorrhage }(3 \%) \\
\text { - Renal }(6 \%)\end{array}$ \\
\hline
\end{tabular}


Table 2 (Continued)

\begin{tabular}{|c|c|c|c|c|c|}
\hline Study & Phase & $\mathbf{N}$ & Eligibility & Regimens & $\begin{array}{l}\text { Grade } 3-4 \text { toxicities in patients } \\
\text { receiving bevacizumab }\end{array}$ \\
\hline & & & & & $\begin{array}{l}\text { - Secondary hematologic } \\
\text { malignancy }(6 \%) \\
\text { - VTE }(3 \%)\end{array}$ \\
\hline Ikeda et al ${ }^{42}$ & II & 19 & Platinum resistant & $\begin{array}{l}\text { B-GEMOX bevacizumab } \\
2 \mathrm{mg} / \mathrm{kg} \text {, gemcitabine } 300 \mathrm{mg} / \mathrm{m}^{2} \text {, } \\
\text { oxaliplatin } 30 \mathrm{mg} / \mathrm{m}^{2} 3 \text { weekly } \\
3 \text { weeks on, I week off }\end{array}$ & $\begin{array}{l}\text { - Gl perforation }(0 \%) \\
\text { - Leukopenia }(16 \%) \\
\text { - Neutropenia }(10 \%) \\
\text { - Thrombocytopenia }(5 \%) \\
\text { - Hand foot syndrome }(5 \%)\end{array}$ \\
\hline Liu et $\mathrm{a}^{41}$ & II & 52 & Platinum resistant & $\begin{array}{l}\text { Bev } 5 \mathrm{mg} / \mathrm{kg} \text { every } 2 \text { weeks + } \\
\text { irinotecan } 60 \mathrm{mg} / \mathrm{m}^{2} \text { weekly }\end{array}$ & $\begin{array}{l}\text { - Gl perforation (0\%) } \\
\text { - HTN (3.8\%) } \\
\text { - VTE (3.8\%) } \\
\text { - Neutropenia (I I.5\%) } \\
\text { - Thrombocytopenia (3.8\%) } \\
\text { - GI (3.8\%) }\end{array}$ \\
\hline \multirow[t]{3}{*}{$\begin{array}{l}\text { Pujade-Lauraine et al }{ }^{9} \\
\text { (AURELIA) }\end{array}$} & III & 361 & Platinum resistant & $\begin{array}{l}\text { Arm I: Bev } 10 \mathrm{mg} \text { every } 2 \text { weeks } \\
+ \text { chemotherapy }\end{array}$ & $\begin{array}{l}\text { - GI perforation }(2.2 \%) \\
\text { - HTN }(7 \%) \\
\text { - Proteinuria }(2 \%)\end{array}$ \\
\hline & & & & Arm 2: chemotherapy alone & $\begin{array}{l}\text { - VTE }(5 \%) \\
\text { - Fistula }(3 \%) \\
\text { - PRES }(1 \%)\end{array}$ \\
\hline & & & & $\begin{array}{l}\mathrm{CT}^{\mathrm{a}}=\text { investigator choice. Paclitaxel } \\
80 \mathrm{mg} / \mathrm{m}^{2} \text { weekly, PLD } 40 \mathrm{mg} / \mathrm{m}^{2} \\
\text { every } 4 \text { weeks or topotecan } \\
4 \mathrm{mg} / \mathrm{m}^{2} \text { weekly or } 1.25 \mathrm{mg} / \mathrm{m}^{2} \\
\text { days } \mathrm{I}-5 \text { every } 3 \text { weeks }\end{array}$ & \\
\hline
\end{tabular}

Note: aDue to the heterogeneity of the chemotherapy arm, rates of toxicity for the Aurelia study are those most likely to be attributable to bevacizumab exposure. A complete list of toxicities can be found in the original reference.

Abbreviations: Bev, bevacizumab; GI, gastrointestinal; HTN, hypertension; VTE, venous thromboembolism; GU, genitourinary; PO, orally; MI, myocardial infarction; PLD, pegylated liposomal doxorubicin; PRES, posterior reversible leukoencephalopathy syndrome; CT, chemotherapy; AURELIA, Avastin Use in Platinum-Resistant Epithelial Ovarian Cancer; GOG, Gynecologic Oncology Group; PD, progression of disease; B-GEMOX, bevacizumab + gemcitabine + oxaliplatin.

early satiety, related to carcinomatosis are among the most burdensome symptoms associated with recurrent metastatic ovarian cancer. Significantly more patients in the bevacizumab arm of the AURELIA trial reported at least a $15 \%$ improvement in their abdominal/GI symptoms $(21.9 \%$ vs $9.3 \%, P=0.002) .{ }^{65}$ The treatment effect was particularly notable in the subset of 113 patients with ascites at baseline, with $44 \%$ of patients in the bevacizumab arm reporting at least $15 \%$ improvement in their GI symptoms (vs $4.1 \%$ with standard chemotherapy alone, $P<0.001) .{ }^{65}$ This observation is likely directly related to the reduction in ascites production. Only $2 \%$ of patients who received bevacizumab required a paracentesis after entering the study when compared to $17 \%$ of patients receiving chemotherapy alone. ${ }^{9}$

Data from the AURELIA trial provide additional support for small case series reporting rapid, complete resolution of previously intractable malignant ascites. ${ }^{66,67}$ Low-dose intraperitoneal bevacizumab has been suggested for the management of malignant ascites. A Chinese randomized controlled trial compared the addition of intraperitoneal bevacizumab $300 \mathrm{mg} / 20 \mathrm{~mL}$ to every 2 weeks intraperitoneal cisplatin $40 \mathrm{mg} / \mathrm{m}^{2}$, with every 3 weeks carboplatin (AUC 5) and paclitaxel $\left(135 \mathrm{mg} / \mathrm{m}^{2}\right)$ in the frontline setting. ${ }^{68}$ After 6 weeks, $58 \%$ (18/31) of the bevacizumab group experienced a complete resolution of ascites when compared to $40.7 \%$ of patients who received cisplatin alone. More significantly, 23/31 patients required no further peritoneal drainage during the 6-week study when compared to 7/27 patients who received cisplatin alone. Peritoneal drainage times were used as proxy for ascites volume and were significantly reduced in the group who received bevacizumab, and intraperitoneal VEGF and CA-125 levels were also significantly lower. While this treatment regimen is somewhat unconventional, intraperitoneal bevacizumab seems to be well tolerated, and there were no grade 3 or 4 toxicities reported.

\section{Other antiangiogenic agents}

There have been a number of other antiangiogenic agents under investigation for the treatment of ovarian cancer. Aflibercept, also known as VEGF-trap, is a heterodimer 
composed of binding domains of VEGFR-1 and VEGFR-2 with an immunoglobulin G Fc domain, which promotes trapping and immune clearance of VEGF. This small molecule has a high affinity for multiple VEGF family ligands, including VEGF-A, -B, and placental growth factor, and was anticipated to have an enhanced activity over bevacizumab. In 2011, Coleman et al reported an ORR of 54\% in a Phase I/II trial of aflibercept with docetaxel for recurrent ovarian cancer. ${ }^{69}$ Tew et al reported a Phase II randomized trial comparing $2 \mathrm{mg} / \mathrm{kg}$ vs $4 \mathrm{mg} / \mathrm{kg}$ aflibercept monotherapy in 215 women with recurrent, platinum-resistant ovarian cancer who had already progressed on PLD or topotecan. Unfortunately, the ORR was very low in both groups $(0.9 \%$ vs $4.6 \%$ ) and did not meet primary endpoints for response. Reported grades 3 and 4 toxicities included hypertension, proteinuria, fatigue, and GI perforation, with rates similar to those reported for bevacizumab. ${ }^{70}$ In light of the role of VEGF in promoting malignant ascites formation, Gotlieb et al designed a third Phase II trial to investigate the potential for aflibercept for palliative ascites reduction. This double blind, placebo control trial of aflibercept $4 \mathrm{mg} / \mathrm{kg}$ every 2 weeks demonstrated a significant prolongation of intervals between palliative paracenteses ( 55.1 days vs 23.3 days, $P=0.0019$ ) but did not confirm a difference in OS. While nonsignificant, the OS in the treatment group was actually shorter (12.9 months vs 16 months), and there was an increased grades 3-4 toxicity, including a GI perforation rate of $10 \%{ }^{71}$ Although the two have not been directly compared, there does not appear to be a compelling advantage of aflibercept over bevacizumab, despite the enhanced VEGF inhibition, and the effect on ascites reduction is not unique.

Because the majority of proangiogenic cell signaling is transmitted through receptor tyrosine kinases, including the VEGFR-1, -2, and -3, PDGF receptor, and FGF receptor, receptor TKIs represent another class of targeted antiangiogenic therapy undergoing intense investigation. Clinical trials examining TKIs and other antiangiogenic drugs are summarized in Table 3. ${ }^{72-84}$ Based on the small studies, TKIs appear to be associated with comparable or somewhat increased rates of grade $\geq 3$ hypertension and rare GI perforations. However, most studies describe dose reductions and drug discontinuation related to other toxicities, including fatigue, diarrhea, mucositis, and dermatologic conditions.

Among the TKIs currently under investigation, cediranib and pazopanib have generated the most promising results. Cediranib is a TKI targeting VEGFR-1, -2, and -3 as well as c-kit. Cediranib was initially tested for the treatment of colorectal and renal cancers with disappointing results. Phase II trials in recurrent ovarian cancer, however, demonstrate
ORRs from $12 \%$ to $17 \%$ in a mixed platinum-sensitive and platinum-resistant population, ${ }^{80,81}$ leading to the development of ICON6, a Phase III trial testing the effect of cediranib combined with carboplatin and paclitaxel with and without maintenance for platinum-sensitive recurrent ovarian cancer, similar in design to the three-arm upfront GOG 218 trial for bevacizumab. Final results of ICON6 are not yet published, but preliminary outcomes were quite exciting. As compared with standard carboplatin and paclitaxel therapy, the addition of cediranib followed by cediranib maintenance resulted in a significantly improved PFS (12.6 months vs 9.4 months, HR $0.57,95 \% \mathrm{CI} 0.45-0.74, P=0.00001)$, and this is the first antiangiogenic drug with an improvement in OS in ovarian cancer (20.3 months vs 17.6 months, HR 0.70, $P=0.0419) .{ }^{82}$ The role of cediranib for platinum-resistant ovarian cancer has not yet been defined, but subgroup data from Phase II studies revealed no ORR among platinum-resistant patients.

Pazopanib is a TKI targeting all three VEGFRs, PDGF receptor, FGF receptor, and c-kit, with additional targets, including colony-stimulating factor 1 , lymphocyte-specific kinase, and IL-2 inducible T-cell kinase. Friedlander et al reported an 18\% ORR among 17 patients with platinumsensitive and -resistant recurrent ovarian cancer. ${ }^{83}$ More exciting, however, are the recently published results from Pignata et al describing a randomized Phase II trial comparing pazopanib $800 \mathrm{mg}$ daily combined with weekly paclitaxel to weekly paclitaxel alone. Combined pazopanib and paclitaxel resulted in an ORR of $56 \%$ with a significant improvement in both PFS (6.35 months vs 3.49 months, HR 0.42, 95\% CI $0.25-0.69, P=0.0002$ ) and a trend toward improved OS (19.1 months vs 13.7 months, HR 0.60, 95\% CI 0.32-1.13, $P=0.56) .{ }^{84}$ The PACOVAR trial, ${ }^{85}$ a Phase I/II study investigating daily metronomic cyclophosphamide in combination with pazopanib, is highly anticipated, and multiple other studies are currently underway.

As an alternative distinct from the VEGF signaling pathway, trebananib (AMG 386) is an antiangiogenic agent targeting angiopoietins Ang1 and Ang2, which signal through their receptor Tie-2, to mediate and stabilize endothelial and tumor vascular integrity. Trebananib was recently evaluated in TRINOVA-1, a Phase III trial that randomized 919 women with recurrent ovarian cancer to trebananib $15 \mathrm{mg} / \mathrm{kg}$ vs placebo in combination with weekly paclitaxel $80 \mathrm{mg} / \mathrm{m}^{2}{ }^{86}$ The trial included patients with both platinum-sensitive and platinum-resistant diseases, which accounted for just $>50 \%$ of the placebo and treatment groups. Trebananib resulted in a prolonged PFS (median PFS 7.2 months vs 5.4 months, HR $0.66,95 \%$ CI $0.57-0.77, P<0.0001$ ), but there was no difference in OS. Unlike bevacizumab, the toxicity profile 


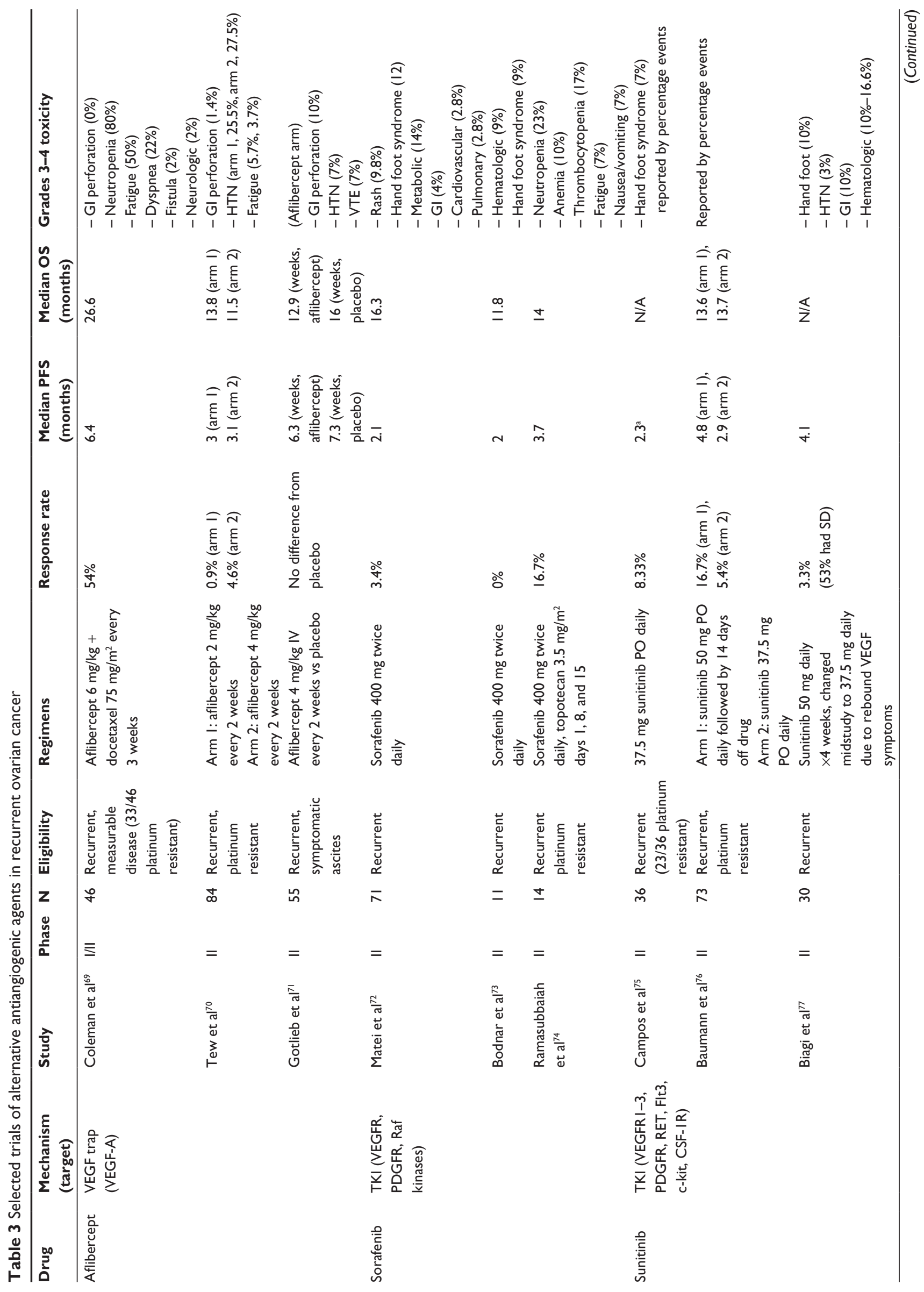




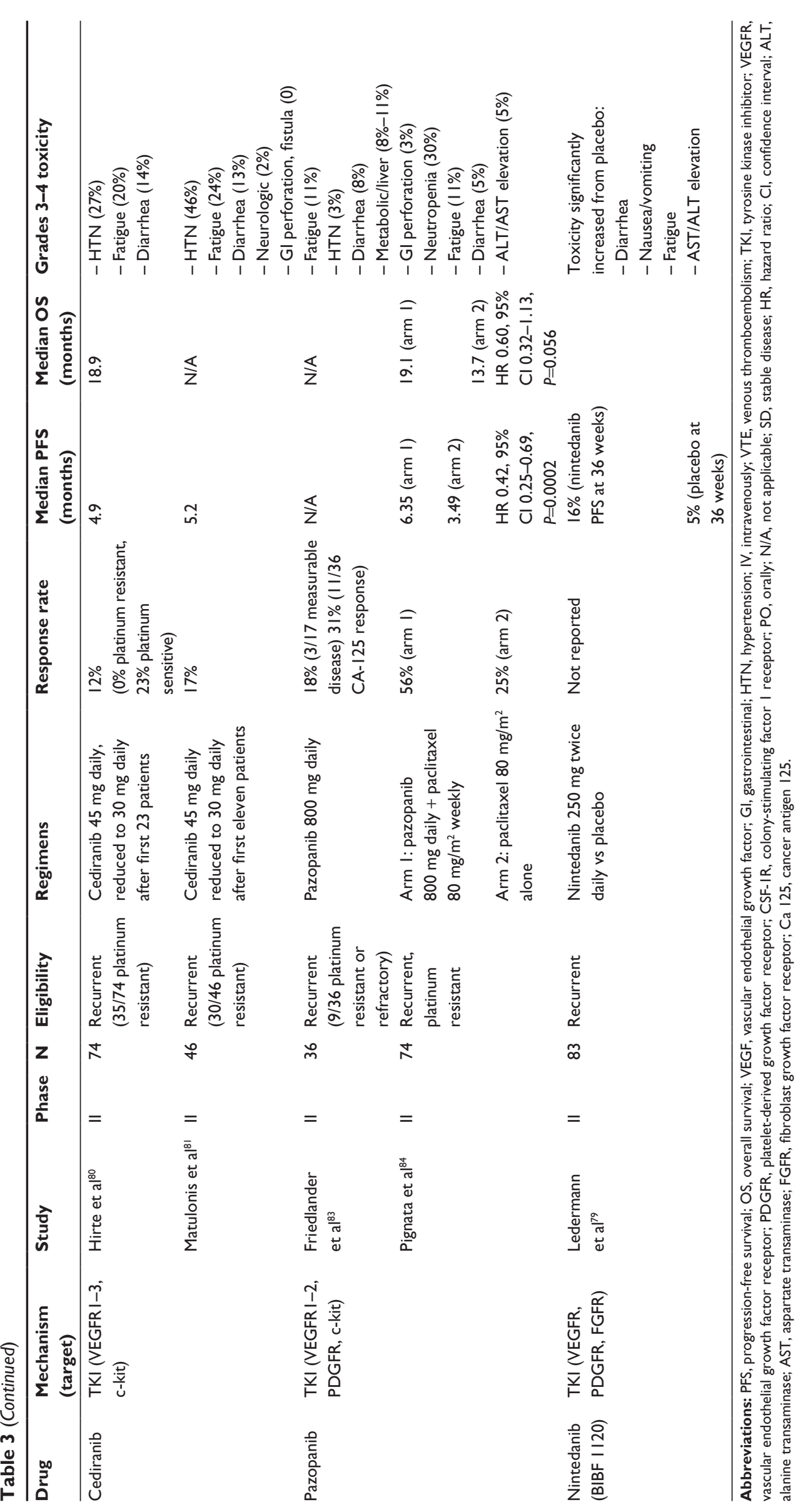


of trebananib includes edema, ascites, and pleural effusions; whereas adverse events typically associated with antiVEGF therapy, including hypertension, proteinuria, and GI perforation, are rare. Trebananib is also being evaluated in combination with PLD in TRINOVA-2 (NCT01281254) and for the frontline setting in combination with carboplatin and paclitaxel in TRINOVA-3 (NCT01493505).

\section{Conclusions and role in therapy}

In Phase III trials in all ovarian cancer treatment settings, the addition of bevacizumab to conventional chemotherapy results in $\sim 2-4$ months increase in median PFS, without a statistically significant improvement in OS. In the recurrent, platinum-resistant setting, bevacizumab monotherapy is well tolerated and appears to have a comparable activity to other nonplatinum chemotherapeutic agents currently in use. When combined with other chemotherapies routinely used for platinum-resistant ovarian cancer, bevacizumab appears to double the expected response rate, with only a modest increase in toxicity. The most common side effects of hypertension and proteinuria can be medically managed with a minimal effect on quality of life. In appropriately screened patients, the rate of GI perforation, hemorrhage, and wound complications is acceptably low.

The role of bevacizumab in controlling ascites and the impact on symptom management and quality of life in the palliative setting are intriguing. Data from the recent AURELIA trial lend support to previous case reports and small case series describing a palliative benefit from reduction in paracentesis-dependent ascites. While not traditionally included in clinical trial outcomes, diminished ascites production on bevacizumab may decrease the need for invasive procedures, and the rate of hospitalization for anorexia and failure to thrive related to symptomatic ascites. An examination of the frontline GOG 218 trial suggested that ascites may act as a predictor of the population of women more likely to have a long-term benefit from bevacizumab. ${ }^{87}$ Aflibercept has been studied for reduction in ascites, but the modest antitumor activity reported suggests no real advantage to bevacizumab. Aflibercept may be a reasonable second-line antiascites therapy for symptomatic patients who do not respond to bevacizumab.

A single optimal dose regimen for bevacizumab has not been established for the treatment of ovarian cancer. Reported dose regimens for bevacizumab include $7.5 \mathrm{mg} / \mathrm{kg}$ every 3 weeks (ICON7), $15 \mathrm{mg} / \mathrm{kg}$ every 3 weeks (GOG 218, OCEANS, and AURELIA), and $10 \mathrm{mg} / \mathrm{kg}$ every 2 weeks (AURELIA). ${ }^{9}$ Bevacizumab has not been tested in humans in doses $>20 \mathrm{mg} / \mathrm{kg} .{ }^{50}$ Both doses evaluated in the AURELIA trial have been approved by the FDA for platinum-resistant ovarian cancer, and we are not aware of any data demonstrating the superiority of one over the other. As the half-life of bevacizumab is $\sim 21$ days, ${ }^{50}$ we favor $15 \mathrm{mg} / \mathrm{kg}$ every 3 weeks. This regimen also coordinates well with 21-day chemotherapy cycles, which are common in the treatment of ovarian cancer; however, every 2 weeks dosing may be more practical for 4-week long cycles, such as with PLD. As chemotherapy in the recurrent, platinumresistant setting is palliative in nature, the duration of therapy should be governed by individual patient goals, response to therapy and/or ability to maintain stable disease, and the toxicities experienced. In the AURELIA trial, therapy with both bevacizumab and chemotherapy was intended to be continued until progression or unacceptable toxicity. We suggest reevaluating response to therapy after three cycles, with ongoing discussions on the duration of therapy. If toxicities emerge that are either chemotherapy or bevacizumab specific, we recommend continuation of the tolerated agent until progression. Bevacizumab may often be continued for many months, or in some cases, years.

The optimal partner to bevacizumab has not been rigorously examined; however, combination with weekly paclitaxel appears to result in the highest ORR, median PFS, and a trend toward improved OS. Although not included in the AURELIA trial, combination therapy with metronomic daily oral cyclophosphamide is a well-tolerated and convenient dosing alternative that may share similar antiangiogenic properties with weekly paclitaxel and may add immunotherapeutic activity as well. Based on the current evidence, choice of cytotoxic chemotherapy for combination with bevacizumab in the recurrent, platinum-resistant setting should be based on the prior treatment history and patient ability to tolerate anticipated toxicities. For patients who may not tolerate combination therapy, bevacizumab monotherapy is a reasonable alternative, with response rates at least comparable to other monotherapy in the platinum-resistant setting and fewer toxicities affecting day-to-day quality of life.

There remain incompletely answered questions regarding bevacizumab in the treatment of platinum-resistant ovarian cancer. One question is the benefit of treating with bevacizumab-based therapy after previous bevacizumab therapy. In colorectal cancer, bevacizumab plus standard second-line chemotherapy in patients with metastatic colorectal cancer progressing after standard first-line bevacizumabbased treatment improved $\mathrm{OS}$ (HR $=0.81, P=0.0062) .{ }^{88}$ Whether this is true in ovarian cancer remains to be seen. However, a retrospective review at a single institution in recurrent ovarian cancer looked at 46 patients who received 
bevacizumab with cytotoxic chemotherapy after having received prior bevacizumab suggested an improved PFS compared to those who did not receive bevacizumab with their cytotoxic therapy. ${ }^{89}$ The ongoing MITO16MANGO2b trial (NCT01802749) aims to evaluate whether patients who have received bevacizumab during the first-line therapy will benefit from bevacizumab in the second-line chemotherapy in platinum-sensitive patients.

Another question is whether sequential therapy of bevacizumab and chemotherapy might offer a similarly efficacious strategy in terms of clinical benefit. Also, that the use of CA-125 in defining progression for patients on bevacizumab may be more limited has been suggested by the findings that $\sim 10 \%-15 \%$ of patients in the single-agent bevacizumab trial for platinum-resistant ovarian cancer (GOG 170D) would have stopped treatment based on CA-125 rather than radiologic evidence of disease progression criteria. ${ }^{90}$ Finally, there remains active, but unestablished, investigation into biomarkers that may be used to define populations most likely to be considered or excluded from bevacizumab therapy. There are a number of ongoing Phase III clinical trials evaluating bevacizumab for ovarian cancer; however, these focus on the primary adjuvant setting or platinum-sensitive disease.

At present, bevacizumab continues to be the most thoroughly studied antiangiogenic therapy for the treatment of recurrent, platinum-resistant ovarian cancer; however, intensive research in the past several years has yielded several promising alternatives. Recent studies of pazopanib have been particularly exciting, and outcomes of ongoing trials are highly anticipated. Combination of bevacizumab with other targeted agents has demonstrated an enhanced antitumor activity at the cost of increased toxicity; however, previously studied targeted therapies have had limited activity on their own, until recently. PARP inhibitors, such as olaparib, represent a significant breakthrough for targeted therapy in ovarian cancer and have demonstrated ORRs of $41 \%$ in BRCA1/2 carriers and $24 \%$ in patients with sporadic tumors. ${ }^{91}$ A Phase II trial evaluating the combination of bevacizumab and olaparib for platinum-sensitive ovarian cancer is currently ongoing. Similar trials for the platinum-resistant population are likely to follow.

Clearly, bevacizumab has added to the arsenal of available treatments for women with epithelial ovarian cancer. This includes the FDA-approved use with chemotherapy in women with recurrent, platinum-resistant ovarian cancer who have had up to two prior chemotherapy regimens. In addition, it appears reasonable to consider the use as a single agent in selected patients of the same population who may not be good candidates for cytotoxic chemotherapy. Data also appear to support a possible benefit in suboptimally cytoreduced patients with high-risk ovarian cancer in the frontline setting. The role in platinum-sensitive disease is less compelling at this time, given the cost and commitment in time for treatment for a relatively modest improvement in PFS without prolonging the survival. There will be more to learn about the appropriate settings and combinations for bevacizumab in the upcoming years.

\section{Disclosures}

Dr Robert M Wenham is a consultant and has received speaking honoraria from the biotechnology company, Genentech, manufacturer of bevacizumab (Avastin) and also received steering committee honoraria from the pharmaceutical company, Amgen. E Clair McClung reports no conflicts of interest in this work.

\section{References}

1. Jemal A, Bray F, Center MM, Ferlay J, Ward E, Forman D. Global cancer statistics. CA Cancer J Clin. 2011;61(2):69-90.

2. Berek JS, Crum C, Friedlander M. Cancer of the ovary, fallopian tube, and peritoneum. Int J Gynaecol Obstet. 2012;119(suppl 2):S118-S129.

3. Davis A, Tinker AV, Friedlander M. "Platinum resistant" ovarian cancer: what is it, who to treat and how to measure benefit? Gynecol Oncol. 2014;133(3):624-631.

4. Gordon AN, Fleagle JT, Guthrie D, Parkin DE, Gore ME, Lacave AJ. Recurrent epithelial ovarian carcinoma: a randomized phase III study of pegylated liposomal doxorubicin versus topotecan. J Clin Oncol. 2001;19(14):3312-3322.

5. Mutch DG, Orlando M, Goss T, et al. Randomized phase III trial of gemcitabine compared with pegylated liposomal doxorubicin in patients with platinum-resistant ovarian cancer. J Clin Oncol. 2007; 25(19):2811-2818.

6. Friedlander M, Millward M, Bell D, et al. A phase II study of gemcitabine in platinum pre-treated patients with advanced epithelial ovarian cancer. Ann Oncol. 1998;9(12):1343-1345.

7. Hoskins P, Swenerton K. Oral etoposide is active against platinumresistant epithelial ovarian cancer. J Clin Oncol. 1994;12(1):60-63.

8. Rose PG, Blessing JA, Mayer AR, Homesley HD. Prolonged oral etoposide as second-line therapy for platinum-resistant and platinumsensitive ovarian carcinoma: a Gynecologic Oncology Group Study. J Clin Oncol. 1998;16(2):405-410.

9. Pujade-Lauraine E, Hilpert F, Weber B, et al. Bevacizumab combined with chemotherapy for platinum-resistant recurrent ovarian cancer: The AURELIA open-label randomized phase III trial. J Clin Oncol. 2014;32(13):1302-1308.

10. Gimbrone MA, Leapman SB, Cotran RS, Folkman J. Tumor dormancy in vivo by prevention of neovascularization. J Exp Med. 1972; 136(2):261-276.

11. Hanahan D, Folkman J. Patterns and emerging mechanisms of the angiogenic switch during tumorigenesis. Cell. 1996;86(3):353-364.

12. Senger DR, Galli SJ, Dvorak AM, Perruzzi CA, Harvey VS, Dvorak HF. Tumor cells secrete a vascular permeability factor that promotes accumulation of ascites fluid. Science. 1983;219(4587):983-985.

13. Leung DW, Cachianes G, Kuang W-J, Goeddel DV, Ferrara N. Vascular endothelial growth factor is a secreted angiogenic mitogen. Science. 1989;246(4935):1306-1309.

14. Ferrara N, Gerber H-P, LeCouter J. The biology of VEGF and its receptors. Nat Med. 2003;9(6):669-676.

15. Schmitt J, Matei D. Targeting angiogenesis in ovarian cancer. Cancer Treat Rev. 2012;38(4):272-283. 
16. Gerber HP, Ferrara N. Pharmacology and pharmacodynamics of bevacizumab as monotherapy or in combination with cytotoxic therapy in preclinical studies. Cancer Res. 2005;65(3):671-680.

17. Gerber H-P, McMurtrey A, Kowalski J, et al. Vascular endothelial growth factor regulates endothelial cell survival through the phosphatidylinositol 3'-kinase/Akt signal transduction pathway requirement for Flk-1/KDR activation. J Biol Chem. 1998;273(46): 30336-30343.

18. Yu Y, Sato JD. MAP kinases, phosphatidylinositol 3-kinase, and p70 S6 kinase mediate the mitogenic response of human endothelial cells to vascular endothelial growth factor. J Cell Physiol. 1999;178(2): 235-246.

19. Dvorak HF, Brown LF, Detmar M, Dvorak AM. Vascular permeability factor/vascular endothelial growth factor, microvascular hyperpermeability, and angiogenesis. Am J Pathol. 1995;146(5):1029.

20. Kraft A, Weindel K, Ochs A, et al. Vascular endothelial growth factor in the sera and effusions of patients with malignant and nonmalignant disease. Cancer. 1999;85(1):178-187.

21. Abu-Jawdeh GM, Faix JD, Niloff J, et al. Strong expression of vascular permeability factor (vascular endothelial growth factor) and its receptors in ovarian borderline and malignant neoplasms. Lab Invest. 1996;74(6):1105-1115.

22. Yamamoto S, Konishi I, Mandai M, et al. Expression of vascular endothelial growth factor (VEGF) in epithelial ovarian neoplasms: correlation with clinicopathology and patient survival, and analysis of serum VEGF levels. Br J Cancer. 1997;76(9):1221.

23. Paley PJ, Staskus KA, Gebhard K, et al. Vascular endothelial growth factor expression in early stage ovarian carcinoma. Cancer. 1997;80(1): 98-106.

24. Shen G, Ghazizadeh M, Kawanami O, et al. Prognostic significance of vascular endothelial growth factor expression in human ovarian carcinoma. Br J Cancer. 2000;83(2):196.

25. Li L, Wang L, Zhang W, et al. Correlation of serum VEGF levels with clinical stage, therapy efficacy, tumor metastasis and patient survival in ovarian cancer. Anticancer Res. 2004;24(3B):1973-1979.

26. Presta LG, Chen H, O'connor SJ, et al. Humanization of an anti-vascular endothelial growth factor monoclonal antibody for the therapy of solid tumors and other disorders. Cancer Res. 1997;57(20):4593-4599.

27. Burger RA, Brady MF, Bookman MA, et al; Gynecologic Oncology Group. Incorporation of bevacizumab in the primary treatment of ovarian cancer. N Engl J Med. 2011;365(26):2473-2483.

28. Perren TJ, Swart AM, Pfisterer J, et al. A phase 3 trial of bevacizumab in ovarian cancer. $N$ Engl J Med. 2011;365(26):2484-2496.

29. Aghajanian C, Blank SV, Goff BA, et al. OCEANS: a randomized, double-blind, placebo-controlled phase III trial of chemotherapy with or without bevacizumab in patients with platinum-sensitive recurrent epithelial ovarian, primary peritoneal, or fallopian tube cancer. J Clin Oncol. 2012;30(17):2039-2045.

30. Aghajanian C, Goff B, Nycum LR, Wang YV, Husain A, Blank SV. Final overall survival and safety analysis of OCEANS, a phase 3 trial of chemotherapy with or without bevacizumab in patients with platinumsensitive recurrent ovarian cancer. Gynecol Oncol. 2015;139(1): $10-16$.

31. Burger RA, Sill MW, Monk BJ, Greer BE, Sorosky JI. Phase II trial of bevacizumab in persistent or recurrent epithelial ovarian cancer or primary peritoneal cancer: a Gynecologic Oncology Group Study. J Clin Oncol. 2007;25(33):5165-5171.

32. Cannistra SA, Matulonis UA, Penson RT, et al. Phase II study of bevacizumab in patients with platinum-resistant ovarian cancer or peritoneal serous cancer. J Clin Oncol. 2007;25(33):5180-5186.

33. Garcia AA, Hirte H, Fleming G, et al. Phase II clinical trial of bevacizumab and low-dose metronomic oral cyclophosphamide in recurrent ovarian cancer: a trial of the California, Chicago, and Princess Margaret Hospital phase II consortia. J Clin Oncol. 2008;26(1):76-82.

34. Matulonis UA, Pereira L, Liu J, et al. Sequential bevacizumab and oral cyclophosphamide for recurrent ovarian cancer. Gynecol Oncol. 2012;126(1):41-46.
35. Wenham RM, Lapolla J, Lin HY, et al. A phase II trial of docetaxel and bevacizumab in recurrent ovarian cancer within 12 months of prior platinum-based chemotherapy. Gynecol Oncol. 2013;130(1):19-24.

36. Tillmanns TD, Lowe MP, Walker MS, Stepanski EJ, Schwartzberg LS. Phase II clinical trial of bevacizumab with albumin-bound paclitaxel in patients with recurrent, platinum-resistant primary epithelial ovarian or primary peritoneal carcinoma. Gynecol Oncol. 2013;128(2):221-228.

37. Verschraegen CF, Czok S, Muller CY, et al. Phase II study of bevacizumab with liposomal doxorubicin for patients with platinum- and taxane-resistant ovarian cancer. Ann Oncol. 2012;23(12):3104-3110.

38. Kudoh K, Takano M, Kouta H, et al. Effects of bevacizumab and pegylated liposomal doxorubicin for the patients with recurrent or refractory ovarian cancers. Gynecol Oncol. 2011;122(2):233-237.

39. McGonigle KF, Muntz HG, Vuky J, et al. Combined weekly topotecan and biweekly bevacizumab in women with platinum - resistant ovarian, peritoneal, or fallopian tube cancer. Cancer. 2011;117(16): 3731-3740.

40. Hagemann AR, Novetsky AP, Zighelboim I, et al. Phase II study of bevacizumab and pemetrexed for recurrent or persistent epithelial ovarian, fallopian tube or primary peritoneal cancer. Gynecol Oncol. 2013;131(3):535-540.

41. Liu Y, Ren Z, Xu S, Bai H, Ma N, Wang F. Low-dose-intensity bevacizumab with weekly irinotecan for platinum- and taxanes-resistant epithelial ovarian cancer. Cancer Chemother Pharmacol. 2015;75(3): 645-651.

42. Ikeda Y, Takano M, Oda K, et al. Weekly administration of bevacizumab, gemcitabine, and oxaliplatin in patients with recurrent and refractory ovarian cancer: a preliminary result of 19 cases. Int J Gynecol Cancer. 2013;23(2):355-360.

43. Kerbel RS. Improving conventional or low dose metronomic chemotherapy with targeted antiangiogenic drugs. Cancer Res Treat. 2007;39(4): $150-159$.

44. Kerbel RS, Kamen BA. The anti-angiogenic basis of metronomic chemotherapy. Nat Rev Cancer. 2004;4(6):423-436.

45. Sistigu A, Viaud S, Chaput N, Bracci L, Proietti E, Zitvogel L. Immunomodulatory effects of cyclophosphamide and implementations for vaccine design. Semin Immunopathol. 2011;33(4):369-383.

46. Chen CA, Ho CM, Chang MC, et al. Metronomic chemotherapy enhances antitumor effects of cancer vaccine by depleting regulatory $\mathrm{T}$ lymphocytes and inhibiting tumor angiogenesis. Mol Ther. 2010;18(6): 1233-1243.

47. Nimeiri HS, Oza AM, Morgan RJ, et al; Chicago Phase II Consortium; PMH Phase II Consortium; California Phase II Consortium. Efficacy and safety of bevacizumab plus erlotinib for patients with recurrent ovarian, primary peritoneal, and fallopian tube cancer: a trial of the Chicago, PMH, and California Phase II Consortia. Gynecol Oncol. 2008;110(1):49-55.

48. Azad NS, Posadas EM, Kwitkowski VE, et al. Combination targeted therapy with sorafenib and bevacizumab results in enhanced toxicity and antitumor activity. J Clin Oncol. 2008;26(22):3709-3714.

49. Reidy DL, Chung KY, Timoney JP, et al. Bevacizumab $5 \mathrm{mg} / \mathrm{kg}$ can be infused safely over 10 minutes. J Clin Oncol. 2007;25(19):2691-2695.

50. Genentec [webpage on the Internet]. Avastin Package Insert. 2015 Available from: www.gene.com/download/pdf/avastin_prescribing pdf. Accessed October 1, 2015.

51. Randall LM, Monk BJ. Bevacizumab toxicities and their management in ovarian cancer. Gynecol Oncol. 2010;117(3):497-504.

52. Izzedine H, Ederhy S, Goldwasser F, et al. Management of hypertension in angiogenesis inhibitor-treated patients. Ann Oncol. 2009;20(5) $807-815$.

53. Kamba T, McDonald D. Mechanisms of adverse effects of anti-VEGF therapy for cancer. Br J Cancer. 2007;96(12):1788-1795.

54. Steeghs N, Rabelink T, de Koning E, Gelderblom H. Bevacizumab-related hypertension: Search for underlying mechanisms. Paper presented at: ASCO Annual Meeting Proceedings, May 29-June 2, 2009; Chicago, IL, USA.

55. Izzedine H. Anti-VEGF cancer therapy in nephrology practice. Int $J$ Nephrol. 2014;2014:143426. 
56. Eremina V, Jefferson JA, Kowalewska J, et al. VEGF inhibition and renal thrombotic microangiopathy. N Eng J Med. 2008;358(11):1129-1136.

57. Seet R, Rabinstein A. Clinical features and outcomes of posterior reversible encephalopathy syndrome following bevacizumab treatment. QJM. 2012;105(1):69-75.

58. Han ES, Monk BJ. What is the risk of bowel perforation associated with bevacizumab therapy in ovarian cancer? Gynecol Oncol. 2007;105(1):3-6.

59. Simpkins F, Belinson JL, Rose PG. Avoiding bevacizumab related gastrointestinal toxicity for recurrent ovarian cancer by careful patient screening. Gynecol Oncol. 2007;107(1):118-123.

60. Scappaticci FA, Skillings JR, Holden SN, et al. Arterial thromboembolic events in patients with metastatic carcinoma treated with chemotherapy and bevacizumab. J Natl Cancer Inst. 2007;99(16):1232-1239.

61. Kozloff M, Yood MU, Berlin J, et al; Investigators of the BRiTE Study. Clinical outcomes associated with bevacizumab-containing treatment of metastatic colorectal cancer: the BRiTE observational cohort study. Oncologist. 2009;14(9):862-870.

62. Seewaldt VL, Greer BE, Cain JM, et al. Paclitaxel (Taxol) treatment for refractory ovarian cancer: phase II clinical trial. Am J Obstet Gynecol. 1994;170(6):1666-1670. discussion 1666-1671.

63. Stark D, Nankivell M, Pujade-Lauraine E, et al. Standard chemotherapy with or without bevacizumab in advanced ovarian cancer: quality-oflife outcomes from the International Collaboration on Ovarian Neoplasms (ICON7) phase 3 randomised trial. Lancet Oncol. 2013;14(3): 236-243.

64. Monk BJ, Huang HQ, Burger RA, et al. Patient reported outcomes of a randomized, placebo-controlled trial of bevacizumab in the front-line treatment of ovarian cancer: a Gynecologic Oncology Group Study. Gynecol Oncol. 2013;128(3):573-578.

65. Stockler MR, Hilpert F, Friedlander M, et al. Patient-reported outcome results from the open-label phase III AURELIA trial evaluating bevacizumab-containing therapy for platinum-resistant ovarian cancer. J Clin Oncol. 2014;32(13):1309-1316.

66. Numnum TM, Rocconi RP, Whitworth J, Barnes MN. The use of bevacizumab to palliate symptomatic ascites in patients with refractory ovarian carcinoma. Gynecol Oncol. 2006;102(3):425-428.

67. Hamilton CA, Maxwell GL, Chernofsky MR, Bernstein SA, Farley JH, Rose GS. Intraperitoneal bevacizumab for the palliation of malignant ascites in refractory ovarian cancer. Gynecol Oncol. 2008;111(3): 530-532.

68. Zhao H, Li X, Chen D, et al. Intraperitoneal administration of cisplatin plus bevacizumab for the management of malignant ascites in ovarian epithelial cancer: results of a phase III clinical trial. Med Oncol. 2015; 32(2):292.

69. Coleman RL, Duska LR, Ramirez PT, et al. Phase 1-2 study of docetaxel plus aflibercept in patients with recurrent ovarian, primary peritoneal, or fallopian tube cancer. Lancet Oncol. 2011;12(12):1109-1117.

70. Tew WP, Colombo N, Ray-Coquard I, et al. Intravenous aflibercept in patients with platinum - resistant, advanced ovarian cancer: results of a randomized, double - blind, phase 2, parallel - arm study. Cancer. 2014;120(3):335-343.

71. Gotlieb WH, Amant F, Advani S, et al. Intravenous aflibercept for treatment of recurrent symptomatic malignant ascites in patients with advanced ovarian cancer: a phase 2, randomised, double-blind, placebocontrolled study. Lancet Oncol. 2012;13(2):154-162.

72. Matei D, Sill MW, Lankes HA, et al. Activity of sorafenib in recurrent ovarian cancer and primary peritoneal carcinomatosis: a gynecologic oncology group trial. J Clin Oncol. 2011;29(1):69-75.

73. Bodnar L, Górnas M, Szczylik C. Sorafenib as a third line therapy in patients with epithelial ovarian cancer or primary peritoneal cancer: a phase II study. Gynecol Oncol. 2011;123(1):33-36.

74. Ramasubbaiah R, Perkins S, Schilder J, et al. Sorafenib in combination with weekly topotecan in recurrent ovarian cancer, a phase I/II study of the Hoosier Oncology Group. Gynecol Oncol. 2011;123(3):499-504.

75. Campos SM, Penson RT, Matulonis U, et al. A phase II trial of Sunitinib malate in recurrent and refractory ovarian, fallopian tube and peritoneal carcinoma. Gynecol Oncol. 2013;128(2):215-220.
76. Baumann K, Du Bois A, Meier W, et al. A phase II trial (AGO 2.11) in platinum-resistant ovarian cancer: a randomized multicenter trial with sunitinib (SU11248) to evaluate dosage, schedule, tolerability, toxicity and effectiveness of a multitargeted receptor tyrosine kinase inhibitor monotherapy. Ann Oncol. 2012;23(9):2265-2271.

77. Biagi J, Oza A, Chalchal H, et al. A phase II study of sunitinib in patients with recurrent epithelial ovarian and primary peritoneal carcinoma: an NCIC Clinical Trials Group Study. Ann Oncol. 2011;22(2):335-340.

78. Hilberg F, Roth GJ, Krssak M, et al. BIBF 1120: triple angiokinase inhibitor with sustained receptor blockade and good antitumor efficacy. Cancer Res. 2008;68(12):4774-4782.

79. Ledermann JA, Hackshaw A, Kaye S, et al. Randomized phase II placebo-controlled trial of maintenance therapy using the oral triple angiokinase inhibitor BIBF 1120 after chemotherapy for relapsed ovarian cancer. J Clin Oncol. 2011;29(28):3798-3804.

80. Hirte H, Lheureux S, Fleming G, et al. A Phase 2 study of cediranib in recurrent or persistent ovarian, peritoneal or fallopian tube cancer: a Trial of the Princess Margaret, Chicago and California phase II consortia. Gynecol Oncol. 2015;138(1):55-61.

81. Matulonis UA, Berlin S, Ivy P, et al. Cediranib, an oral inhibitor of vascular endothelial growth factor receptor kinases, is an active drug in recurrent epithelial ovarian, fallopian tube, and peritoneal cancer. J Clin Oncol. 2009;27(33):5601-5606.

82. Ledermann JA, Perren TJ, Raja FA, et al. Randomized double-blind phase III trial fo cediranib (AZD 2171) in replased platinum sensitive ovarian cancer: results of the ICON6 trial. Poster presented at: European Cancer Congress; Sept 27- Oct 1, 2013; Amsterdam.

83. Friedlander M, Hancock KC, Rischin D, et al. A phase II, open-label study evaluating pazopanib in patients with recurrent ovarian cancer. Gynecol Oncol. 2010;119(1):32-37.

84. Pignata S, Lorusso D, Scambia G, et al. MITO-11: A randomized multicenter phase II trial testing the addition of pazopanib to weekly paclitaxel in platinum-resistant or-refractory advanced ovarian cancer (AOC). Paper presented at: ASCO Annual Meeting Proceedings, May 30-June 3, 2014; Chicago, IL, USA.

85. Eichbaum M, Mayer C, Eickhoff R, et al. The PACOVAR-trial: a phase I/II study of pazopanib (GW786034) and cyclophosphamide in patients with platinum-resistant recurrent, pre-treated ovarian cancer. BMC Cancer. 2011;11(1):453.

86. Monk BJ, Poveda A, Vergote I, et al. Anti-angiopoietin therapy with trebananib for recurrent ovarian cancer (TRINOVA-1): a randomised, multicentre, double-blind, placebo-controlled phase 3 trial. Lancet Oncol. 2014;15(8):799-808.

87. Ferriss JS, Java JJ, Bookman MA, et al. Ascites predicts treatment benefit of bevacizumab in front-line therapy of advanced epithelial ovarian, fallopian tube and peritoneal cancers: an NRG Oncology/GOG study. Gynecol Oncol. 2015;139(1):17-22.

88. Bennouna J, Sastre J, Arnold D, et al; ML18147 Study Investigators. Continuation of bevacizumab after first progression in metastatic colorectal cancer (ML18147): a randomised phase 3 trial. Lancet Oncol. 2013;14(1):29-37.

89. Backes FJ, Richardson DL, McCann GA, et al. Should bevacizumab be continued after progression on bevacizumab in recurrent ovarian cancer? Int J Gynecol Cancer. 2013;23(5):833-838.

90. Randall LM, Sill MW, Burger RA, Monk BJ, Buening B, Sorosky JI. Predictive value of serum CA-125 levels in patients with persistent or recurrent epithelial ovarian cancer or peritoneal cancer treated with bevacizumab on a Gynecologic Oncology Group phase II trial. Gynecol Oncol. 2012;124(3):563-568.

91. Gelmon KA, Tischkowitz M, Mackay H, et al. Olaparib in patients with recurrent high-grade serous or poorly differentiated ovarian carcinoma or triple-negative breast cancer: a phase 2, multicentre, open-label, non-randomised study. Lancet Oncol. 2011;12(9):852-861.

92. Poveda AM, Selle F, Hilpert F, et al. Bevacizumab combined with weekly paclitaxel, Pegylated liposomal doxorubicin, or topotecan in platinum-resistant recurrent ovarian cancer: analysis by chemotherapy cohort of the randomized phase III AURELIA trial. J Clin Oncol. Epub 2015 Aug 17. 
International Journal of Women's Health

Dovepress

\section{Publish your work in this journal}

The International Journal of Women's Health is an international, peerreviewed open-access journal publishing original research, reports, editorials, reviews and commentaries on all aspects of women's healthcare including gynecology, obstetrics, and breast cancer. The manuscript management system is completely online and includes

Submit your manuscript here: http://www.dovepress.com/international-journal-of-womens-health-journa a very quick and fair peer-review system, which is all easy to use. Visit http://www.dovepress.com/testimonials.php to read real quotes from published authors. 